\title{
Cambios fisiológicos y mecanismos genéticos asociados a la marchitez vascular causada por Fusarium en tomate: una revisión actualizada
}

\section{Physiological and genetic changes associated to vascular wilt of tomato caused by Fusarium: an updated review}

\author{
Sandra L. Carmona ${ }^{1}$; Andrea Villarreal-Navarrete ${ }^{1 \oplus}$; \\ Diana Burbano-David ${ }^{1}$; Mauricio Soto-Suárez ${ }^{*} \oplus^{\prime}$
}

Recibido para publicación: agosto 10 de 2020 - Aceptado para publicación: diciembre 27 de 2020

\section{RESUMEN}

El cultivo de tomate (Solanum lycopersicum L.), una de las hortalizas más cultivadas en el mundo, se enfrenta a diferentes patógenos del suelo que afectan su morfología, fisiología, bioquímica y regulación genética de las plantas. El hongo fitopatógeno Fusarium oxysporum f. sp. lycopersici (Fol) agente causal de la marchitez vascular del tomate causa pérdidas superiores al $60 \%$ en este cultivo. En esta revisión se presentan los mecanismos fisiológicos, bioquímicos y moleculares desarrollados en la interacción tomate - Fol. La co-evolución entre plantas y patógenos ha facilitado el desarrollo de mecanismos de defensa en las plantas que les permite protegerse frente a los efectos nocivos de la invasión por parte del patógeno, mientras que los patógenos implementan estrategias para imponerse frente a la resistencia de las plantas. Las consecuencias fisiológicas del ataque por Fol incluyen respuestas al déficit hídrico, regulaciones en la conductancia estomática, cambios en la fotosíntesis, así como alteraciones en los contenidos de clorofila y su fluorescencia. Estos cambios pueden ser explicados, en parte, con base en respuestas oxidativas, producción de metabolitos secundarios y activación de vías de señalización hormonales que hacen parte de una compleja red bioquímica activada tras la infección por el patógeno.

Palabras clave: Solanum lycopersicum; Estrés biótico; Estrés osmótico; Regulación de la expresión génica.

'Corporación Colombiana de Investigación Agropecuaria Agrosavia. Centro de Investigación Tibaitatá, Mosquera, Cundinamarca-Colombia.

*Autor para correspondencia: Mauricio Soto-Suárez

Email:msoto@agrosavia.co

\section{ABSTRACT}

Tomato (Solanum lycopersicum L.) is a worldwide commercially important grown vegetable. Tomato plants are infected by different soil-borne pathogens that affect morphology, physiology, biochemistry and genetic regulation of plants. Fusarium oxysporum f. sp. lycopersici (Fol) is the causal agent of Fusarium wilt of tomato and causes significant yield losses-up to $60 \%$ - in tomato crops. This review presents the physiological, biochemical and molecular mechanisms undertaken in the tomato-Fol interaction. The co-evolution between plants and pathogens has allowed the development of an immune system to protect plants against the pathogen invasion, while pathogens implement strategies to overcome plant defense responses. Physiological consequences of $F$. oxysporum infection include responses to water deficit, regulation of stomatal conductance, influence on photosynthesis, chlorophyll fluorescence and chlorophyll content. These physiological and molecular changes can be, at least, partially explained by the activation of different processes, such as oxidative responses, secondary metabolites production and induction of hormone signal pathways, as part of a complex biochemical network activated during the infection.

Keywords: Solanum lycopersicum; Biotic stress; Osmotic stress; Regulation of gene expression.

\section{Cómo citar}

Carmona, S.L., Villarreal-Navarrete, A., Burbano-David, D. y Soto-Suárez, M. 2020. Cambios fisiológicos y mecanismos genéticos asociados a la marchitez vascular causada por Fusarium en tomate: una revisión actualizada. Temas Agrarios 25(2):166-189.

https://doi.org/10.21897/rta.v25i2.2457 


\section{INTRODUCCIÓN}

El tomate (Solanum lycopersicum L.) es una de las hortalizas más cultivadas en el mundo. Para el año 2019, en Colombia se registraron 4.677 hectáreas (ha) productivas de tomate en invernadero, en las que se produjeron 446.366 toneladas $(\mathrm{t})$, con un rendimiento promedio de 95,44 t.ha ${ }^{-1}$, mientras en campo abierto se reportaron 13.146 ha sembradas, produciendo $336.034 \mathrm{t}$, con un rendimiento promedio de 2,56 t.ha-1 (Agronet, 2020). El cultivo ha conservado una tendencia nacional creciente, con un aumento en casi 300.000 toneladas cosechadas en los últimos 10 años (FAO, 2020).

El cultivo del tomate es afectado por diferentes tipos de estreses bióticos y abióticos, los cuales afectan la morfología, fisiología, bioquímica y regulación genética de las plantas (Kavroulakis et al., 2018; Kumar y Verma, 2018); entre los bióticos se encuentran los microorganismos fitopatógenos, que impactan directamente en el rendimiento del cultivo (Kumar y Verma, 2018; Wiesel et al., 2014). Muchos de estos microorganismos se hospedan en el suelo, destacándose el hongo Fusarium oxysporum (Dean et al., 2012) que causa pérdidas superiores al 60\% (Villa-Martínez et al., 2015).

Fusarium oxysporum causa síntomas de marchitez vascular en más de 150 especies vegetales y cuenta con un amplio rango de formae speciales (f. sp.) según el hospedero que infecta. En tomate, se reporta a $F$. oxysporum f. sp. lycopersici $(F o l)$, el cual permanece latente en el suelo mediante clamidosporas, hasta por 20 años y germinan en cercanía de la raíz del hospedero cuando las condiciones son propicias (Srinivas et al., 2019; Dean et al., 2012; Michielse y Rep, 2009; Di Pietro et al., 2003). Las hifas del hongo crecen y forman una intrincada red alrededor de los pelos radicales, ubicando los puntos de penetración en la unión de las células epidermales, atraviesa el córtex y avanza hasta el xilema, el cual usa para invadir la planta con la proliferación de sus hifas y microconidias. Estas estructuras fúngicas dentro de los vasos del xilema, sumadas a secreciones de polisacáridos y enzimas pectinolíticas (Figura 1) disminuyen o bloquean el flujo de agua y nutrientes en la planta (Srinivas et al., 2019).

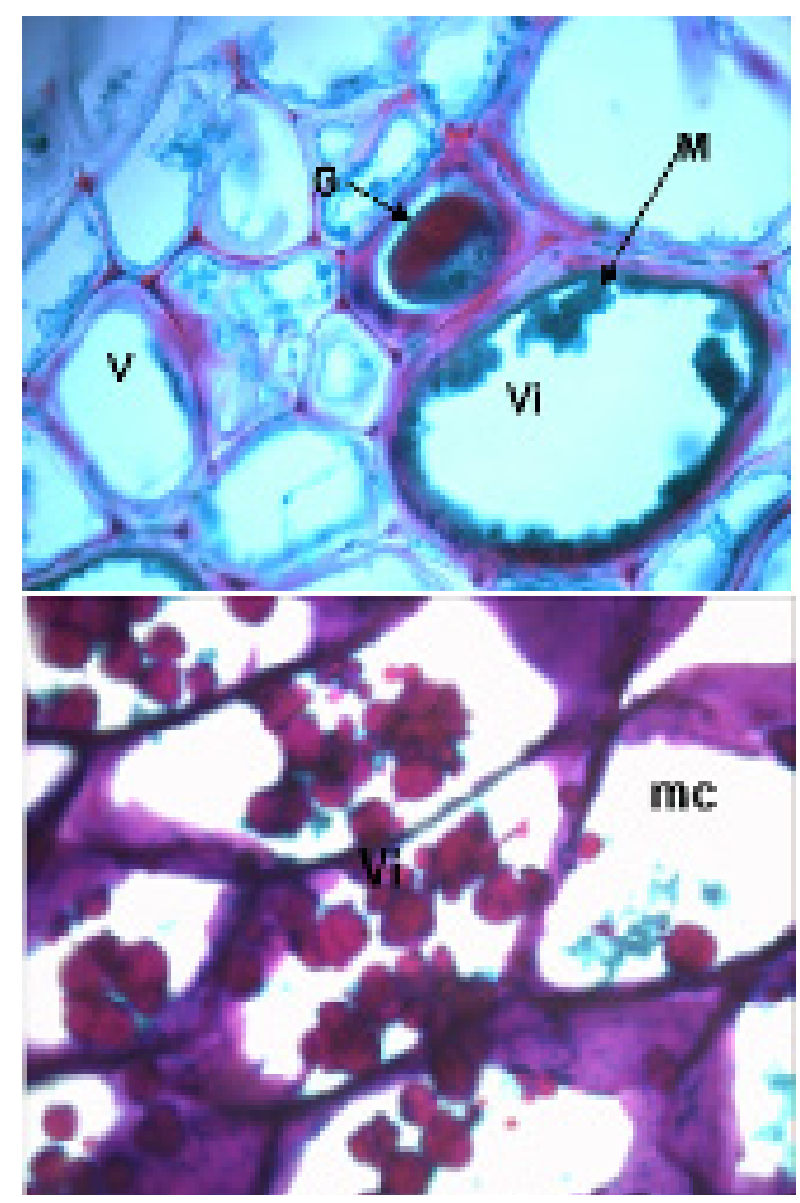

Figura 1. Corte transversal del cuello de raíz de uchuva (Physalis peruviana) inoculada con F. oxysporum 20 días después de infección. Aumento de 100X. M, Micelio; V, Vasos del xilema sanos; Vi, vasos del xilema infectados; G, Gomas; mc, microconidias. Técnica de tinción: contraste con safranina y fast-green. (Tomado de: Villarreal, 2013)

La obstrucción de los haces vasculares ocasionados por Fol produce síntomas visuales similares a los observados en plantas bajo estrés hídrico severo (Chekali et al., 2011; Srinivas et al., 2019), presentan una coloración pardo- 
oscura en el tejido vascular, amarillamiento, marchitez foliar y finalmente la muerte. En condiciones de campo, la marchitez vascular es más evidente en las etapas de floración y llenado de frutos; $y$ se ve favorecida por condiciones de altas temperaturas $\left(28^{\circ} \mathrm{C} \pm 2\right)$, $\mathrm{pH}$ bajo del suelo, uso de fertilizantes amoniacales y la aplicación frecuente de riego que mantenga el suelo por encima de capacidad de campo (Boix-Ruíz et al., 2015; Abbashar, 2003; Clayton, 1923).

En la relación planta patógeno, las plantas han desarrollado defensas constitutivas, tales como la acumulación de toxinas microbianas, además de mecanismos de defensa inducibles tras el reconocimiento del patógeno (RamírezGómez y Rodríguez, 2012). Un aspecto clave de este sistema de respuesta inducida, es su activación tras la detección de moléculas genéricas conservadas en un amplio rango de microorganismos y patógenos (denominadas MAMPs o PAMPs de sus siglas en inglés Microbial or Pathogen associated Molecular Patterns, o elicitores) (Ádám et al., 2018; Vidhyasekaran, 2016; Jones y Dangl, 2006). Algunos ejemplos conocidos de elicitores o MAMPs incluyen las flagelinas, los lipopolisacaridos o el factor de elongación Tu de bacterias, la quitina de hongos, el péptido Pep13 de oomicetos y los hectaglucósidos, entre otros (Jones y Takemoto, 2004). Estas moléculas MAMPs son reconocidas por receptores de membrana (PRRs, por sus siglas en inglés Patern Recognition Receptors) presentes en todas las células vegetales, que han sido preservados evolutivamente y permiten la detección temprana de los patógenos.

La percepción de estas moléculas elicitoras desencadena una serie de cascadas de señalización que Ilevan a la activación de la respuesta de defensa que incluye, entre otros, la generación rápida de especies reactivas de oxígeno, la producción de fitohormonas señalizadoras (ácido salicílico, ácido jasmónico y etileno), el refuerzo de la pared celular (lignificación, deposición de calosa), la síntesis de compuestos antimicrobianos (fitoalexias y otros metabolitos secundarios) y la inducción de genes de defensa (muchos de ellos codifican proteínas con actividad antimicrobiana) (Maqsood et al., 2020; van Loon et al., 2006). Otro concepto clave, es que esta respuesta de defensa es general y no específica frente al agente invasor, confiriendo la capacidad de inmunizar a la planta frente a un amplio espectro de patógenos.

En las plantas existe otra respuesta de defensa inducible, activada por el reconocimiento específico de moléculas efectoras del patógeno, a través de proteínas de resistencia de la planta, denominada inmunidad mediada por efectores (ETI, Efector-Triggered Immunity) o resistencia específica (Andersen, et al., 2018; Boller y Felix, 2009). Esta respuesta se manifiesta usualmente asociada a la respuesta hipersensible (HR, Hypersensitive Response) (Walters, 2015; Wiesel et al., 2014; Henry et al., 2012; Jones y Dangl, 2006), caracterizada por la formación de lesiones necróticas en el punto de infección (Walters, 2015). Aunque es activada por un mecanismo de reconocimiento más específico, la respuesta de defensa específica es similar a la basal, con las principales diferencias en la amplitud y el tiempo de inducción de los procesos defensivos. Además de la respuesta de defensa local, los tejidos atacados son capaces de generar señales móviles de alerta que activan una respuesta de defensa sistémica en tejidos distantes al foco de infección (Shah, 2009). Esta respuesta sistémica es duradera y de amplio espectro.

Existen dos tipos de respuesta sistémica, la denominada SAR (del inglés, Systemic Acquired Resistance) desencadenada por el ataque de patógenos y dependiente de la acumulación de ácido salicílico, y la ISR (del inglés, Induced Systemic Resistance) desencadenada por la colonización de las raíces por microorganismos benéficos del suelo y dependiente de la acumulación de las 
hormonas ácido jasmónico y etileno (Andersen et al., 2018; Pitzschke et al., 2009; Shah, 2009). Estas respuestas sistémicas pueden ser inducidas por diversos compuestos sintéticos tales como el INA (2,6-dichloroisinicotinic acid) $\mathrm{O}$ el BTH (S-methyl venzo-1,2,3thiadiazole-7-carbothiate). En general, se considera que durante la respuesta de defensa sistémica, las plantas están sensibilizadas para la activación rápida y fuerte de las acciones de defensa (efecto priming), más que presentar una inducción constitutiva de los mecanismos de defensa que supondrían un costo energético importante para la planta (Beckers y Conrath, 2007).

En tomate, se han identificado al menos 65 genes $\mathrm{R}$ que reconocen patógenos virulentos (Chaudhary y Atamian, 2017). Esta información ha permitido el desarrollo de híbridos de tomate tolerantes a Fol. La respuesta bioquímica y molecular de la interacción tomate-Fol, y del efecto de las estrategias de manejo que se han implementado, ha sido ampliamente estudiada, sin embargo, es poco lo que se ha profundizado en los efectos sobre los rasgos fisiológicos del tomate durante esta interacción. En las siguientes secciones se discutirán y revisarán algunos de los parámetros fisiológicos, bioquímicos y moleculares que son alterados durante la interacción hospedero-patógeno, y las respuestas activadas por la planta.

\section{MECANISMOS FISIOLÓGICOS DE LA RESPUESTA DE LA PLANTA A}

Fusarium oxysporum $f$. sp. lycopersici.

Déficit hídrico: uno de lo síntomas más claros y visibles que se producen durante la infección por $\mathrm{Fol}$ es la pérdida de turgencia en las hojas, además de la defoliación y clorosis típicos de un déficit hídrico severo. El patógeno ingresa desde las raíces, hasta alcanzar los haces vasculares (Yadeta y Thomma, 2013). Las microconidias e hifas del hongo dentro del xilema, sumadas a secreciones de polisacáridos y enzimas pectinolíticas disminuyen el potencial hídrico en las hojas y los tallos (Srinivas et al., 2019; Duniway, 1971) como resultado de la obstrucción en los haces vasculares, sumado a la inyección de moléculas efectoras que bloquean la defensa de la planta y toxinas que generan daño celular. En plantas de tomate infectadas con $\mathrm{Fo} /$ se han observado reducciones de hasta 2,6 veces en el potencial hídrico y de $18 \%$ en el CRA (Contenido Relativo de Agua) a los 31 días después de inoculación (ddi) (Nogués et al, 2002); además, pueden reducir el flujo de agua en la planta hasta en un $95 \%$, causando cierre estomático y reducción en la tasa de transpiración (Walters, 2015). Duniway en 1971, encontró un aumento cercano al 50\% en la resistencia al movimiento de agua en plantas infectadas con Fol (10-16 ddi), pero turgentes a simple vista; mientras que en plantas infectadas y con síntomas de marchitez, el incremento fue del $100 \%$. Además, las lesiones generadas por el patógeno en su ingreso hasta el xilema también contribuyen en la obstrucción de los haces vasculares (Brodersen y McElrone, 2013).

Conductancia estomática: La conductancia estomática entendida como la medida de la velocidad de paso de $\mathrm{CO}_{2}$ o vapor de agua a través de los estomas de una hoja, se relaciona con la apertura estomática en respuesta a la disponibilidad de agua desde las raíces (Azcón-Bieto y Talón, 2008). Los grados de apertura o cierre estomático están mediados por la concentración de ABA, y la producción de MAPKs (proteínas quinasas activadas por mitógenos), ROS (del inglés, reactive oxygen species) y de óxido nítrico (NO), que se pueden generar en respuesta ante eventos de estrés biótico y abiótico (Qi et al., 2018). La restricción en el movimiento de agua a través

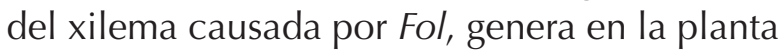
un desbalance hídrico que induce en ella el cierre estomático para evitar la pérdida de agua (Nankishore y Farrell, 2016). El cierre estomático ocasionado por la infección, parece ser uno de los factores que más afecta la 
asimilación de $\mathrm{CO}_{2}$, además de correlacionar con disminuciones en el potencial hídrico de la hoja de tomate (Nogués et al., 2002). De acuerdo con Lorenzini et al., (1997), la conductancia estomática es uno de los primeros parámetros afectados en la interacción tomate-Fol después de siete días de infección se empieza a reducir dicho parámetro, alcanzando valores hasta de un 50\% de disminución (Akhter et al., 2015).

Contenido de clorofilas: la clorofila es responsable de la absorción de la luz dirigida a la fotosíntesis, por lo cual, la disminución en el contenido o cambios en la proporción de clorofilas a y b, supone una alteración fisiológica en las plantas de tomate (Marín-Ortiz, Gutierrez-Toro, Botero-Fernández, y HoyosCarvajal, 2020). Varios autores han encontrado que $\mathrm{Fo} /$ reduce el contenido de clorofilas totales (a y b) en plantas de tomate entre los 4 y los 30 ddi (Maqsood et al., 2020; Zehra et al., 2017; Pshibytko et al., 2006; Lorenzini et al., 1997).

Se considera que uno de los principales factores en la disminución de clorofilas se debe a que el estrés hídrico por el bloqueo vascular, causa cierre estomático y consecuentemente puede ocurrir fotorrespiración, acumulación de ROS, y daño irreversible a los cloroplastos (Singh et al., 2017). Se ha comprobado que el ácido fusárico, una de las principales toxinas producidas por Fol (Singh et al., 2017; Maina et al., 2008), funciona como factor de patogenicidad $y$ causa trastornos como hiperpolarización de membranas (celulares y tilacoidales), pérdida de electrolitos, disminución en la síntesis de clorofilas y peroxidación lipídica (López-Díaz et al., 2017; Singh y Upadhyay, 2014; Jiao et al., 2013; Samadi y Behboodi, 2006). Por otro lado, se ha reportado previamente que bajos niveles de magnesio en la hoja debido a la disminución en la toma de nutrientes por el bloqueo del sistema vascular, ralentizan el proceso de síntesis de clorofila, dándose así una descompensación entre la degradación y síntesis de nuevas clorofilas (Dehgahi et al., 2015).
Fotosíntesis: Varios estudios han demostrado que la infección por $\mathrm{Fol}$ en plantas de tomate produce reducciones en fotosíntesis neta y en variables relacionadas con la eficiencia fotosintética, tales como transpiración y actividad estomática, como consecuencia del déficit hídrico y la escasez de nutrientes (Maqsood et al., 2020; Pinheiro y Chaves, 2011; Chaves et al., 2009; Nogués et al., 2002). Plantas de tomate infectadas con Fol después de 14 días de infección, presentaron un decrecimiento significativo de la fotosíntesis neta, condición que causó un impacto negativo en el funcionamiento de los pigmentos fotosintéticos y la actividad del fotosistema II (PSII), dando como resultado lesiones cloróticas en las hojas (Lorenzini et al., 1997; Maqsood et al., 2020)

El desarrollo de clorosis en las hojas de plantas afectadas por Fol, se debe en parte al avance del patógeno por los haces vasculares y a la circulación del ácido fusárico hacia las hojas. Tales síntomas pueden observarse en tejidos distantes (hojas superiores) al punto de avance de la infección (Dong et al., 2014; Maina et al., 2008). En este sentido, Singh et al., (2017), concluyeron que la alteración en el aparato fotosintético en hojas de tomate, es consecuencia del estrés oxidativo causado por el daño que el ácido fusárico provoca en las membranas celulares y tilacoidales; en sus experimentos obtuvieron reducciones hasta del $60 \%$ en la fotosíntesis neta de las hojas después de 4 horas de tratamiento con ácido fusárico, además observaron una degradación de pigmentos fotosintéticos, acumulación de $\mathrm{H}_{2} \mathrm{O}_{2}$ y peroxidación lipídica.

Durante la infección por $\mathrm{Fol}$ se presentan afectaciones directas sobre los procesos fotosintéticos de carboxilación y fijación del $\mathrm{CO}_{2}$, así como en la actividad de enzimas relacionadas con el ciclo de Calvin. Tales afectaciones son, en parte, consecuencia del descenso en los valores de conductancia estomática y las disminuciones en la 
concentración de clorofilas que afectan procesos lumínicos de la fotosíntesis (Walters, 2015). Pshibytko et al., (2006) hallaron una disminución en la actividad de la ribulosa1,5-bifosfato carboxilasa/oxigenasa (RuBisCO) durante la infección por Fol. Además, Nogués et al., (2002) encontraron que la enfermedad puede reducir hasta en un $25 \%$ la conductancia estomática, disminuir la fotosíntesis neta, la velocidad de carboxilación de la RuBisCO y la capacidad de regeneración de la ribulosa-1,5-bifosfato (RuBP). Algunos patógenos incluyendo $\mathrm{Fol}$ son capaces de alterar la expresión de genes relacionados con la fotosíntesis reduciendo los componentes esenciales en el complejo captador de luz y de fijación de carbono (Huot et al., 2014).

Fluorescencia de la clorofila: Las clorofilas, y en menor medida los carotenoides, son pigmentos vegetales responsables de la absorción de fotones de luz usados en los procesos de conversión de energía lumínica. Estos pigmentos se encuentran inmersos dentro de las proteínas fotosintéticas formando complejos pigmento-proteína, conformados por el fotosistema II (PSII), el fotosistema I (PSI), asociados a sus respectivas antenas $\mathrm{LHCl}$ y LHCII (del inglés, Light Harvesting complexes) y el complejo citocromo b6f (Azcón-Bieto y Talón, 2008). Cuando la clorofila absorbe el fotón de luz, este puede ser dirigido a tres procesos, la producción de ATP a través de la cadena de transporte de electrones o disipación fotoquímica (pQ), la reemisión de luz a una longitud de onda mayor que es el fenómeno conocido como fluorescencia y la desviación de los fotones como emisión de calor o disipación no fotoquímica (NPQ).

La fluorescencia de la clorofila se usa para determinar el estado de distribución de la energía lumínica y la eficiencia cuántica del PSII. Por la sensibilidad de este fotosistema, la fluorescencia de la clorofila ha sido utilizada como un indicador de estrés en plantas, incluyendo tomate (Wang et al., 2018; Baker, 2008; Maxwell y Johnson, 2000). Los principales indicadores de la fluorescencia son: la Fv/Fm (máxima eficiencia cuántica fotoquímica del PSII) que indica la cantidad de fotones absorbidos por el PSII para la reducción de la plastoquinona A cuando todos los centros de reacción están abiertos; la disipación fotoquímica ( $\mathrm{qP}$ ) que indica la capacidad de transmitir los electrones desde el PSII hacia el PSI para producir ATP y la eficiencia fotoquímica del PSII (Y(II)) que revela la capacidad de usar la energía captada en la fase fotoquímica de la fotosíntesis (Melgarejo et al., 2010).

La reducción en los parámetros de fluorescencia es gradual según el progreso de la marchitez por Fusarium. Lorenzini et al., (1997) y Maqsood et al., (2020), evaluaron diferentes parámetros fotosintéticos en plantas infectadas con $\mathrm{Fol}$ y encontraron reducciones en los valores de Fv/Fm de 5\% y 8,4\%, a los 14 ddi, lo cual atribuyeron a una disminución en la fluorescencia variable y una alteración en el PSII. De igual manera Maqsood et al., (2020), observaron reducciones en $\mathrm{Y}(\mathrm{II})$, qP y ETR (transporte de electrones tilacoidal) de $15 \%, 11,7 \%$ y $8,8 \%$, respectivamente. En otro estudio realizado por Pshibytko et al., (2006) los valores de $\mathrm{Fv} / \mathrm{Fm}$ disminuyeron un 11\%, los valores de $\mathrm{Y}(\mathrm{II})$ un $30 \%$, y qP un $13 \%$; mientras los valores de NPQ aumentaron el doble en plantas infectadas con Fol. Los autores atribuyeron esta disminución a diferentes fenómenos ocurridos durante el proceso de infección, tales como, la dificultad en la toma de agua, el déficit de nutrientes y la acción de las micotoxinas licomarasmina, ácido fusárico y vasinfuscarina. En otros trabajos realizados donde se infectaron plantas de tomate con Fol, Nogués et al., (2002) encontraron, después de 25 días de infección, una reducción en los valores de Y(II) del 50\%, y disminuciones para $\mathrm{Fv}^{\prime} / \mathrm{Fm}^{\prime}$ y qP en un 27 y $28 \%$, respectivamente. Dada la afectación tardía de estos parámetros, los autores consideran que son la consecuencia 
de una disminución en la asimilación de $\mathrm{CO}_{2}$ en las hojas. La disminución en Y(II) es atribuida a una baja en el transporte de electrones durante la fase lumínica de la fotosíntesis, la cual puede deberse a una reducción en la demanda de NADPH+ y ATP en la fase oscura de la fotosíntesis (Dehgahi et al., 2015; Nogués et al., 2002).

Dada la sensibilidad de la fluorescencia de la clorofila ante eventos de estrés y la relación que existe entre este proceso y las etapas de absorción y conversión de la energía lumínica como la fotólisis del agua, el transporte de electrones y la síntesis de ATP, esta variable permite evaluar el estado de la fotosíntesis de la planta (Goltsev et al., 2016; Melgarejo et al., 2010). Además, según Wagner et al., (2006), la fluorescencia de la clorofila también puede ser usada como un indicador del marchitamiento por Fusarium en tomate, haciendo uso de la correlación inversamente proporcional entre el índice de severidad de la enfermedad y los valores de Y(II).

Varios estudios han demostrado el impacto sobre la actividad fotosintética de la planta de tomate generado por las infecciones de $F$. oxysporum, con reducciones hasta del $85 \%$ en las tasas de asimilación neta. En estos estudios también fue posible observar alteraciones en el estado hídrico de la planta, con disminuciones del $18 \%$ en el CRA, reducciones en la conductancia estomática que van desde el $65 \%$ hasta el $86 \%$, afectaciones en la transpiración con decrecimiento hasta del $78 \%$ y descenso en el uso eficiente del agua (Maqsood et al., 2020; Pshibytko et al., 2006; Nogués et al., 2002; Lorenzini., 1997). Todo lo anterior, tiene como consecuencia un impacto negativo sobre la acumulación de biomasa en la planta.

El crecimiento de las plantas se ve afectado por un desbalance que se presenta en las vías de señalización hormonal a causa del estrés biótico. Durante la respuesta de defensa se activan, entre otras, las vías de señalización del ácido salicílico y ácido jasmónico que pueden interferir con otras vías hormonales de crecimiento como las mediadas por auxinas, giberelinas y brasinosteroides, necesarias en diferentes procesos de crecimiento y desarrollo (Huot et al., 2014). Por otro lado, la baja síntesis de azúcares debida a las reducciones en las tasas de asimilación neta y la demanda de las fuentes de carbono; y de la asimilación de hexosas por parte de los patógenos principalmente en la fase biótrofa, impactan negativamente el crecimiento de las plantas (Dehgahi et al., 2015; Berger et al., 2004). De hecho, el efecto de $\mathrm{Fol}$ sobre parámetros de crecimiento de la planta de tomate, se ha constatado en varios estudios, demostrando que hay una reducción significativa en la altura de la planta, área foliar y la masa fresca y seca (Constantin et al., 2019; Nogués et al., 2002).

\section{MECANISMOS BIOQUÍMICOS DE LA RESPUESTA DE LA PLANTA A PATÓGENOS}

Respuesta oxidativa: los procesos de producción de ROS como el peróxido de hidrógeno $\left(\mathrm{H}_{2} \mathrm{O}_{2}\right)$, el anión superóxido $\left(\mathrm{O}_{-}{ }_{2}\right)$, y el radical hidroxilo $(-\mathrm{OH})$, son constantes y dinámicos como resultado de procesos metabólicos que requieren transporte de electrones. Estas moléculas se producen en cantidades relativamente bajas y las plantas cuentan con un sistema antioxidante muy eficaz conformado por pigmentos, moléculas y enzimas antioxidantes que reducen rápidamente las ROS para evitar que causen daños en el sistema (Tripathy y Oelmüller, 2012). La producción de ROS se activa también en la respuesta local frente a microorganismos biótrofos, contribuyendo en la aparición de la respuesta hipersensible. En condiciones de estrés, se activan diversos mecanismos de defensa para mantener el equilibrio oxidativo, principalmente del sistema antioxidante (Figura 2). Además, las ROS son mensajeros secundarios que participan en la activación 
de diferentes cascadas de señalización y la expresión de genes de defensa, relacionados con respuesta sistémica de la planta frente al patógeno (Tripathy y Oelmüller, 2012; FraireVelázquez et al., 2011). Existen dos tipos de mecanismos para disipar el daño oxidativo causado por ROS, el sistema no enzimático (aminoácidos, ácido ascórbico, polifenoles, antocianinas, carotenoides, glutatión, chalconas, tocoferoles, entre otros), y el sistema enzimático (peroxidasa, ascorbato peroxidasa, catalasa, glutatión reductasa, superóxido dismutasa, entre otras) (Latowski et al., 2010; Melgarejo et al., 2010)

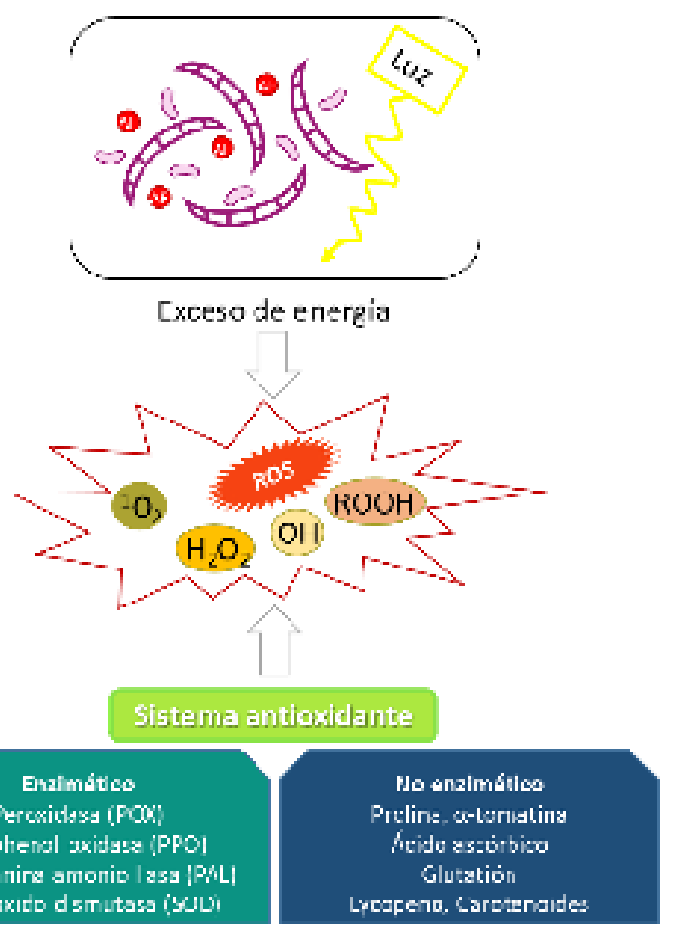

Figura 2. Respuesta oxidativa de las plantas frente a estrés biótico. El sistema antioxidante de la planta posibilita la regulación de los niveles de ROS (Adaptado de: Latowski et al., 2010).

El hongo Folposee micotoxinas que inducen una alta producción de ROS a nivel celular (Singh et al., 2017). La activación rápida del sistema antioxidante por parte de la planta de tomate aumenta la capacidad de la planta para resistir la enfermedad; varios estudios han encontrado que plantas infectadas por $\mathrm{Fol}$ incrementaron significativamente la acumulación de $\mathrm{H}_{2} \mathrm{O}_{2^{\prime}}$ acompañada de una baja actividad del sistema antioxidante; mientras que, plantas con altos niveles de actividad enzimática antioxidante presentaban mayor resistencia a la enfermedad (Singh et al., 2020; Jayamohan et al., 2018; Basco et al., 2017). Así mismo, Maqsood et al., (2020), observaron aumentos en la concentración de malondialdehido (MDA), $\mathrm{H}_{2} \mathrm{O}_{2}$ y prolina; y una baja actividad antioxidante en plantas de tomate susceptibles a Fol.

Las enzimas antioxidantes peroxidasa (POX), polyphenol oxidasa (PPO), phenylalanine ammonia-lyasa (PAL) y superóxido dismutasa (SOD), están involucradas en una extensa red de defensa de las plantas ante agentes patogénicos. POX es una glicoproteína que se oxida en presencia de $\mathrm{H}_{2} \mathrm{O}_{2}$ y que además está involucrada en diferentes reacciones redox en la membrana plasmática, metabolismo del etileno y modificaciones de la pared celular y biosíntesis de lignina. PPO es una enzima que cataliza los radicales $\mathrm{O}_{2}$, e incrementa la actividad antimicrobiana (Narasimhamurthy et al., 2019) .

Plantas de tomate infectadas con Fol dependen de la capacidad de activar efectivamente su sistema antioxidante, a través de las enzimas APX (ascorbato peroxidasa), SOD, PPO y CAT (catalasa); para contrarrestar las cascadas oxidativas activadas por la respuesta al patógeno y disminuir los daños causados por ROS (Jayamohan et al., 2018). Estas enzimas antioxidantes están relacionadas con diferentes mecanismos de inducción de resistencia en plantas de tomate contra Fol (Singh et al., 2020; Mandal et al., 2009)

Cuando se presentan eventos de estrés abiótico como sequía, inundación, salinidad, temperaturas extremas, radiación UV y metales pesados, pero principalmente ante un estrés hídrico, las plantas buscan ajustar su potencial 
osmótico para mantener la turgencia y volumen celular, y de esta manera garantizar un continuo funcionamiento del aparato fotosintético.

Este ajuste en el potencial osmótico se realiza mediante la síntesis y acumulación de solutos en la vacuola, tales como la prolina, un metabolito que funciona como agente osmótico u osmoprotectante junto con la glicin-betaína, ectoína y los azúcares (fructosa, sacarosa, mioinositol, trehalosa y fructanos) (Yang et al., 2011; Ashraf y Foolad, 2007). La prolina es además una de las moléculas que protege y estabiliza el ADN, las membranas y las proteínas de los daños causados por ROS en respuestas oxidativas; (Choudhary y Varma, 2016; Ben Rejeb et al., 2014). De esta manera, el aumento en el contenido de prolina en las plantas se considera como un indicador de la capacidad de tolerar eventos de estrés abiótico (Freitas De Campos et al., 2011; Yang et al., 2011; Arbona et al., 2010), dadas las funciones que posee la prolina como osmolito compatible y agente antioxidante (Freitas De Campos et al., 2011).

En la interacción Fol-tomate, la prolina puede funcionar como indicador de estrés. Alsamir et al., (2017) y Soliman y El-Mohamedy, (2017) encontraron en ambos trabajos una relación directa entre la severidad de la enfermedad y el contenido de prolina, en cuyo caso, su acumulación puede no ser suficiente para proteger los sistemas dañados por la respuesta oxidativa inducida por el patógeno. Por otro lado, Zehra et al., (2017) observaron que plantas infectadas y con menor mortalidad por Fol, acumularon mayores cantidades de prolina. Los diferentes estudios sugieren que la prolina de forma individual no disminuye el estrés oxidativo de plantas enfermas, sino que actúa conjuntamente con el resto del sistema antioxidante.

\section{METABOLITOS SECUNDARIOS EN LA RESPUESTA A PATÓGENOS VASCULARES}

Las plantas también sintetizan gran cantidad de metabolitos secundarios implicados en la respuesta de defensa. Existen tres tipos principales de metabolitos secundarios: los compuestos fenólicos, los terpenos y los compuestos que contienen Nitrógeno/Azufre, los cuales están involucrados además en diferentes procesos de crecimiento y desarrollo. Los metabolitos secundarios aumentan su producción y se activan tras la detección de MAMPs por parte de la planta, además algunos estudios sugieren que la mayoría de los metabolitos secundarios poseen características antifúngicas (Zaynab et al., 2018).

Los fenoles y flavonoides constituyen un gran grupo de fitoquímicos y juegan un papel importante en la defensa frente a la radiación UV y enfermedades. Los fenoles cambian la permeabilidad celular de los microorganismos y causan cambios estructurales y funcionales de las proteínas de membrana, lo que resulta en alteraciones del gradiente de $\mathrm{pH}$, el sistema de producción y conservación de ATP, las enzimas de membrana y la utilización del sustrato para la producción de ATP. Por ejemplo, la a-tomatina una saponina presente en plantas de tomate, activa proteínas-G y fosfotirosinakinasas, las cuales se unen a la membrana celular llevando al aumento en la producción de ROS y la elevación de $\mathrm{Ca}^{+2}$ en defensa ante infecciones de $F$. oxysporum (Ito et al., 2007). Altos contenidos de fenoles, así como una alta actividad de la enzima PPO se han relacionado con inducción de resistencia en plantas de tomate, y una consecuente disminución de la severidad en plantas infectadas por Fol (Manokaran y Jambhulkar, 2016). 


\section{EL PAPEL DE LAS FITOHORMONAS EN LA REGULACIÓN DE LAS INTERACCIONES PLANTA PATÓGENO}

Los procesos de respuesta de defensa de las plantas frente a diferentes condiciones de estrés comprenden mecanismos moleculares y bioquímicos complejos que desencadenan respuestas fisiológicas en la planta (Atkinson y Urwin, 2012). El sistema de defensa en las plantas es regulado por una intrincada red de señalización en el que las fitohormonas, principalmente el ácido salicílico (AS), ácido jasmónico (AJ) y el etileno (ET), le confieren a la planta la capacidad de regular la activación de los sistemas de defensa ante diferentes agentes estresantes (Pieterse et al., 2009). Tras la detección de la condición de estrés, las fitohormonas modulan la respuesta inmune como un sistema que se retroalimenta positiva o negativamente y mantiene su homeostasis en la planta (Couto y Zipfel, 2016). Las fitohormonas son pequeñas moléculas orgánicas requeridas en bajas concentraciones, para regular funciones como crecimiento, desarrollo, reproducción y respuesta de defensa (Huot et al., 2014).

Ácido salicílico (AS): El papel de esta hormona en la interacción planta-patógeno, se ha descrito principalmente en procesos de defensa local y sistémica frente a patógenos biótrofos y hemibiótrofos participando en la resistencia sistémica adquirida de la planta (SAR, del inglés Systemic Acquired Resistance). Además, esta hormona participa en el crecimiento, desarrollo y senescencia vegetal (Huot et al., 2014). La defensa mediada por AS puede activar o ser activada por MAPKs y finaliza en la activación de factores de transcripción para promover la expresión de genes relacionados con patogenicidad (genes PR) (Andersen et al., 2018).

Aplicaciones de AS a nivel foliar, son capaces de inducir resistencia sistémica frente a patógenos fúngicos y bacterianos (Narasimhamurthy et al., 2019; Mandal et al., 2009). Mandal et al., (2009) realizaron aplicaciones exógenas de AS en plantas de tomate y encontraron que las plantas tratadas con la fitohormona, y luego inoculadas con Fol, presentaron una importante reducción en la marchitez vascular y el amarillamiento foliar. Los autores concluyeron que esta reducción de la enfermedad indica una resistencia sistémica adquirida dependiente del AS.

Ácido jasmónico (AJ): es una hormona derivada de ácidos grasos, involucrada en procesos de defensa contra patógenos necrótrofos y daños mecánicos o por insectos. La vía de señalización del AJ antagoniza con la vía del AS reprimiendo su activación, lo que es usado por algunos patógenos biótrofos capaces de controlar para su beneficio las vías del AJ/ET, evitando de esta manera la expresión de la vía del AS para disminuir la capacidad de respuesta de la planta (Carvalhais et al., 2013; MartínezMedina et al., 2013; Pieterse et al., 2012). El AJ y su versión metilada (Metil jasmonatoMeJA) más volátil y móvil, funcionan como molécula señal a nivel sistémico en la planta (Vidhyasekaran, 2016).

Aunque se asume que las vías del AS y el AJ son completamente antagónicas por activarse frente a biótrofos y necrótrofos, respectivamente, varios autores han encontrado que, en plantas de tomate, bajo la inducción por microorganismos benéficos (Trichoderma sp., hongos micorrizícos, bacterias, etc), el AJ y su derivado el MeJA, regulan los mecanismos de la respuesta de defensa de la planta frente a Fol, en una respuesta tipo ISR (del inglés, Induced Systemic Resistance) (Jogaiah et al., 2018; Zehra et al., 2017; Król et al., 2015; Nair et al., 2015).

Etileno (ET): es una hormona gaseosa que juega un papel importante en la respuesta inmune a través de una señalización sistémica y además induce la expresión de genes de defensa 
(Pieterse et al., 2012). Normalmente, el ET actúa de forma sinérgica con el $\mathrm{AJ}$, aunque también se ha descrito su interacción con AS tanto de forma sinérgica como antagónica, dependiendo del patosistema (Dmitriev, 2003). Varios estudios han constatado la participación del ET en reacciones de susceptibilidad de plantas de tomate frente a Fol (Di et al., 2017; Francia et al., 2007; Lund et al., 1998), aunque otros estudios han demostrado lo contrario durante la inducción de ISR por microorganismos endófitos (Kavroulakis et al., 2007).

No hay una conclusión unánime en cuanto a las sinergias e interferencias hormonales en la interacción tomate- Fol. La compleja maquinaria hormonal activada por la planta en contra del patógeno, las condiciones ambientales o experimentales, la biología del patógeno y el genotipo del hospedero, pueden representar enormes variaciones en la intercomunicación hormonal de la planta que no permite generalizar conceptos. Por esto, es necesario profundizar en estudios bajo condiciones biogeográficas específicas y analizar cada caso separadamente. La descripción de algunos mecanismos transcripcionales, por los cuales se dan las intercomunicaciones hormonales en respuesta a $F$. oxysporum, y particularmente a Fol, se describen en la siguiente sección.

\section{MECANISMOS GENÉTICOS DE DEFENSA DE LA PLANTA}

En su interacción con microorganismos, las plantas continuamente se encuentran sometidas a presiones por parte de patógenos, sin embargo, poseen un mecanismo de respuesta complejo que les permite protegerse frente a los efectos nocivos de la invasión (van der Does et al., 2018). La co-evolución entre plantas y patógenos ha sido conocida como una carrera armamentista, donde las plantas desarrollan mecanismos de defensa mientras que los patógenos implementan estrategias para imponerse frente a la resistencia de las plantas (Stahl et al., 2000).
En algunos cultivos de hortalizas, se ha reportado resistencia de tipo monogénica frente a formas especiales de F. oxysporum (Michielse y Rep, 2009). Es así como bajo el concepto del modelo gen por gen, la resistencia de la planta depende de una interacción específica entre las proteínas codificadas por los genes de resistencia del huésped $(R)$ y las que codifican los genes de avirulencia (AVR) del patógeno (Periyannan et al., 2017; Rep et al., 2004). De acuerdo con el modelo mencionado, los genes $\mathrm{R}$ determinan la especificidad del sistema de defensa en la planta (van der Does et al., 2018), codificando proteínas NLR (de NB and LRR containing protein) que son capaces de reconocer las proteínas efectoras del patógeno durante el proceso de infección en el huésped (Periyannan et al., 2017; Jones et al., 2016;).

En la interacción entre tomate y Fol, se han identificado varios genes de Resistencia o genes I (Immunity), sin embargo, pese a que las plantas exhiben cierto grado de resistencia, no siempre el patógeno es controlado por completo (van der Does et al., 2018), como ocurre en este patosistema donde el hongo es capaz de colonizar y propagarse desde las raíces hasta el tallo antes de detener su invasión (Mes et al., 2000). Posterior al reconocimiento de $\mathrm{Fo} /$ mediado por los genes $I$, se induce una respuesta de defensa en las células parenquimatosas adyacentes a los vasos xilemáticos, donde en lugar de una respuesta hipersensible se desencadenan respuestas como depósitos de calosa, acumulación de compuestos fenólicos y formación de tilosas y gomas en los vasos infectados (Takken y Rep, 2010).

En el caso particular de la marchitez por Fusarium en tomate, el patógeno Fol se clasifica en tres razas fisiológicas definidas, de acuerdo con su capacidad de infectar diferentes cultivares que poseen genes de resistencia I (García-Enciso et al., 2018; Takken y Rep, 2010). De esta manera, las interacciones 
compatibles o incompatibles son controladas por los genes de avirulencia en Fol y los genes de inmunidad (genes $I$ ) en tomate (Inami et al., 2012). Las variedades de tomate con resistencia a una o varias razas fisiológicas de $\mathrm{Fo} /$ se han desarrollado a partir de la introgresión de genes de especies silvestres como Solanum pennellii y S. pimpinellifollium (van der Does et al., 2018; Chaudhary y Atamian, 2017). Estos cultivares mejorados pueden presentar resistencia a las razas 1, 2 o ambas, además en algunos casos pueden ser resistentes a las tres razas del hongo (incluyendo la raza 3) (McGovern, 2015). Los tres efectores de $\mathrm{Fol}$ son reconocidos por los tres genes I de la planta (Rep et al., 2004).

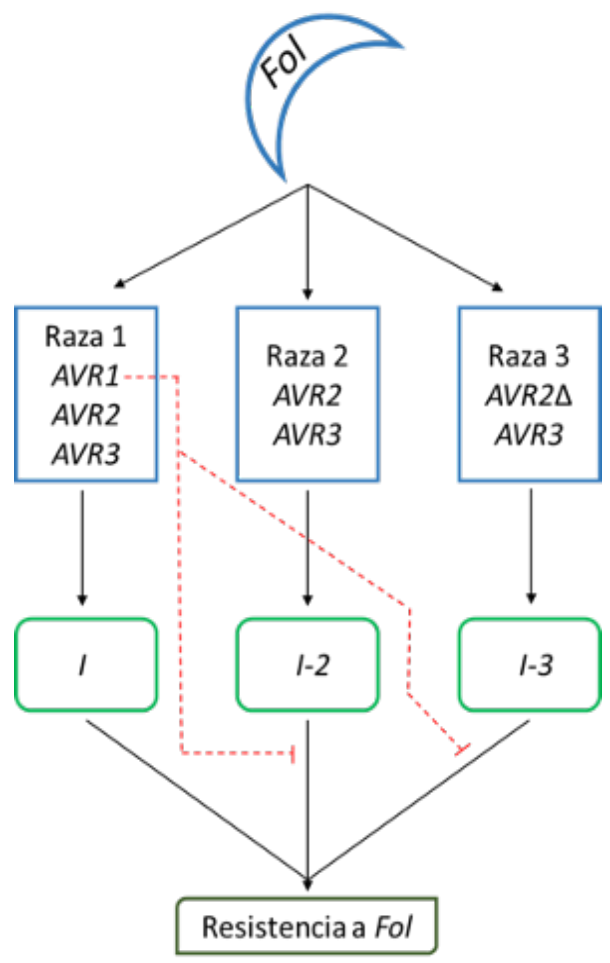

Figura 3. Interacción de los genes AVR de Fol y los genes I en tomate (Adaptado de: García-Enciso et al., 2018).

Como se observa en la figura 3, los genes I, l-2 e I-3 confieren protección contra Fol raza 1 (que posee los genes AVR1, AVR2 y $A V R 3$ ), Fol raza 2 (pérdida de $A V R 1$, posee $A V R 2$ y AVR3) y Fol raza 3 (pérdida de AVR1, contiene gen $A V R 2$ con mutaciones puntuales y AVR3), respectivamente (Catanzariti et al., 2017; Inami et al., 2012; Takken y Rep, 2010). Adicionalmente, se ha reportado que la proteína codificada por el gen $A V R 1$, tiene la capacidad de suprimir la resistencia mediada por los genes l-2 e l-3 (Houterman et al., 2008).

Además de los genes de resistencia mencionados, se han identificado los genes I-1 (que reconoce $A V R 1$ ) e $1-7$, este último confiere resistencia a las razas 1,2 y 3 de Fol y la resistencia no es suprimida por AVR1 (Gonzalez-Cendales et al., 2016), sin embargo, los mecanismos moleculares de esta resistencia no han sido descritos aún. Se ha reportado también, que las plantas con respuestas mediadas por los receptores extracelulares I e l-3 son más eficaces para restringir la propagación fúngica que las mediadas por el receptor intracelular l-2 (van der Does et al., 2018).

Por su parte, toda modulación de respuesta a nivel bioquímico y fisiológico en plantas tiene una base genética. En general, una de las vías de señalización mejor descritas es la red hormonal. Gran parte de la investigación es sobre el papel de las hormonas en la defensa frente a patógenos ha sido estudiada en plantas de Arabidopsis thaliana L. La descripción del mecanismo hormonal en esta planta y la confirmación en otros patosistemas de muchos de los supuestos encontrados allí, ha permitido generar un modelo de intercomunicación hormonal de la respuesta de defensa ante patógenos.

El modelo permite entender que cuando se activa la vía hormonal del AS, el gen NPR 1 (NON EXPRESSOR OF PR GENES1) funciona como coactivador transcripcional de genes $P R$ que desencadenan una respuesta de defensa frente a patógenos biótrofos, gracias a la transcripción de genes asociados a proteínas antimicrobianas (Pieterse et al., 2012). Uno de los genes PR más 
ampliamente estudiado es el PR1 (PATHOGEN RESPONSE1) que se expresa como respuesta a la síntesis y señalización por AS (Nobori et al, 2018; Saharan y Pal, 2016). Esta misma vía de señalización induce la expresión de otro gen denominado PAL (PHENYLALANINE AMMONIA LYASE), que codifica una enzima clave en una de las vías de síntesis de AS, a través del metabolismo de los fenilpropanoides y el incremento de contenidos fenólicos, para una respuesta de resistencia a enfermedades (Kiirika et al., 2013; Pusztahelyi, 2018; Sharif et al., 2018).

Las plantas de $A$. thaliana son susceptibles F. oxysporum f.sp. conglutinans (Focn), un microorganismo biótrofo. Las líneas transgénicas que expresan la enzima bacteriana silicato hidroxilasa (NahG), o plantas mutantes en el gen sid2 (del inglés, $S A$ induction-deficient $2)$, no pueden acumular $A S$ en su sistema. Ambas líneas, sobre-expresión de NahG y mutante sid2, presentan un incremento en la susceptibilidad al patógeno, lo que demuestra que el AS está involucrado en la respuesta de defensa a Focn (Di et al., 2017).

Como se mencionó anteriormente, las vías de señalización del AS y del AJ son fuertemente antagónicas, lo cual ha sido demostrados a través de la expresión del gen NPR1, activado en la ruta del AS y que regula negativamente la vía de señalización del AJ (Thaler et al., 2012). Sin embargo, recientes estudios encontraron una vía en la cual ciertas concentraciones de AS activan las proteínas receptoras NPR3 y NPR4 que a su vez interactúan con JAZ (parte del complejo represor de la síntesis de AJ), para inducir la síntesis de esta molécula (Pieterse et al., 2009). Este puede ser uno de los puntos de interacción en las respuestas simultáneas ante microorganismos biótrofos y necrótrofos (Liu et al., 2016; Pieterse et al., 2009).

Plantas de $A$. thaliana con insensibilidad al ET gracias a la mutación en el gen ETHYLENE
INSENSITIVE2-1 (EIN2-1) y en el gen ETHYLENE RECEPTOR1 (ETR1-1) mostraron una reducción en la sintomatología de Focn (Di et al., 2017). Adicionalmente, la mutación en genes que tienen actividad en la ruta de biosíntesis del AJ tales como JASMONATE RESISTANT1 (JAR1-1) y ALLENE OXIDE SYNTHASE (AOS), así como en un gen involucrado en la percepción del A), CORONATINE INSENSITIVE1 (COI1), y en factores que regulan la transcripción en la ruta de señalización del AJ como MYC2, PFT1 y LBD20, dieron como resultado plantas más resistentes a Focn, comprobando que tanto el ET como el JA juegan un papel fundamental en la susceptibilidad de las plantas de $A$. thaliana ante Focn (Figura 4) (Di et al., 2017; Jia et al., 2013; Doares et al., 1995).

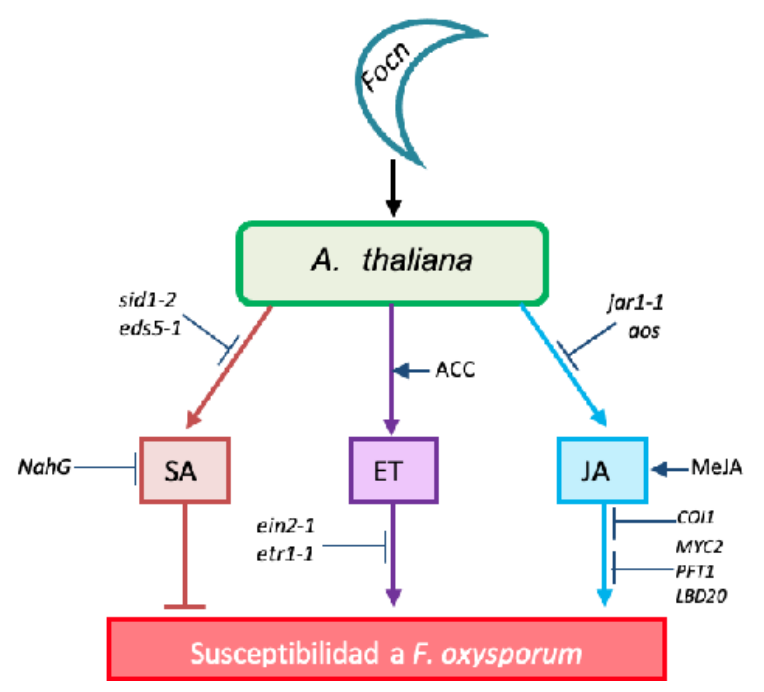

Figura 4. Modelo de la red hormonal en la activación de respuestas de defensa en Arabidopsis thaliana L., frente a Fusarium oxysporum f. sp. conglutinans (Focn). Las barras truncadas representan regulación negativa. Las flechas representan regulación positiva. Adaptado de (Di et al., 2017).

Para entender el papel de estas hormonas en la interacción de $F$. oxysporum con plantas de tomate, se realizaron las mismas modificaciones genéticas descritas en el modelo de Arabidopsis, en plantas de tomate de variedades susceptibles a Fol. Usando plantas transgénicas de tomate que sobre expresan la enzima bacteriana NahG, se 
confirmó que el SA interviene positivamente en la defensa ante Fol. Los síntomas de marchitez vascular observados en plantas deficientes en acumulación de AS fueron más severos que en plantas control de la variedad susceptible. Estas observaciones fueron confirmadas a través de la detección de la inducción del gen marcador $P R 1 a$, el cual no fue expresado en las plantas transgénicas de NahG (Di et al., 2017).

Por otra parte, los trabajos realizados en $A$. thaliana para entender la vía de señalización del AJ en la defensa contra Focn, permitieron observar el papel que juega esta hormona en la expresión de síntomas de marchitez. Sin embargo, las mutaciones realizadas sobre los genes def1 y jai1 en plantas de tomate y expuestas a Fol, no muestran diferencias significativas en la severidad de los síntomas de la enfermedad, permitiendo suponer que esta hormona no tiene un efecto importante sobre la interacción (Di et al., 2017). El contraste de resultados en varios trabajos que han buscado entender el rol del AJ en la interacción de Fusarium con sus hospederos es evidente. Así como en la interacción tomate-Fol, Di et al, (2017), encontraron que esta hormona no tiene un rol importante en el desarrollo de la enfermedad, mientras otros investigadores han encontrado que algunas formas especiales de F. oxysporum sí muestran sensibilidad a esta vía de señalización, aumentando los síntomas de marchitez en las plantas hospedero. Tal es el caso de F.oxysporum f. sp. conglutinans (Foc), F.oxysporum f. sp. matthioli (Fom) y F. oxysporum f. sp. raphani (For), que sintetizan JA y lo usan como efector en su respectivo hospedero, aumentando la enfermedad y la infección en las raíces. Es importante mencionar que en este mismo trabajo se encontró que la infección por Fol no induce la producción de AJ (Cole et al., 2014). Por el contrario, en batata (Ipoemea batata), la infección con $F$. oxysporum f. sp. batatas (Fob) activa el factor de transcripción IbBBX24, que modula la transcripción de los genes JAZ-MYC, requeridos para la activación de la señalización por AJ, aumentando la resistencia ante el patógeno (Zhang et al., 2020).

Otros trabajos en plantas de tomate dan cuenta de la diversidad en la respuesta de defensa inducida por la vía del AJ frente a Fol. Por ejemplo, Jogaiah et al., (2018) demostraron que se indujo la expresión del gen PDF1 mediada por el biocontrolador Trichoderma virens, simultáneamente, a la activación de genes relacionados con el AS (PR1). Esta respuesta redujo la severidad de la enfermedad, confirmando que existe una participación importante por parte del AJ en la respuesta inmune de plantas de tomate frente a $\mathrm{Fol}$, pero que se requiere mantener una interconexión con la vía del AS. Constantin et al., (2019) también observaron que plantas deficientes en la vía de señalización del AJ, fueron más susceptibles a Fol. Por otro lado, Król et al., (2015) aplicaron MeJA de forma exógena en plántulas de tomate y observaron un incremento en la síntesis de componentes fenólicos, así como en la concentración de AS, asociados a la disminución de la enfermedad por Fol.

Los hallazgos contrastantes en los diferentes trabajos sugieren que la intercomunicación hormonal para la respuesta a Fol es dependiente de condiciones específicas tanto del patógeno como del hospedero; y esto puede estar relacionado tanto con la agresividad de las diferentes cepas patogénicas, como con la base genética del hospedero que puede determinar su grado de susceptibilidad.

En A. thaliana, los factores de transcripción ERF (factores de respuesta a etileno) de la ruta de señalización del ET se activan tras la infección por F. oxysporum. En tomate, la expresión del gen PTI4, miembro de la familia de los ERFs, es inducida tras la infección con Fol. La inducción de PTI4 y ERF4, fue confirmada en plantas de tomate susceptibles a Fol, mientras que en plantas mutantes $A C D$, la expresión de estos genes fue muy baja. Las plantas $A C D$ contienen 
la enzima ACCd que cataliza la degradación del ACC (precursor del ET). Bajo este panorama, la investigación alrededor del papel del ET en la defensa a Fol, fue complementada observando los síntomas de marchitez en plantas mutadas en el gen $N r$, que otorga insensibilidad al ET, en las cuales no fue posible visualizar síntomas asociados a Fol. Estos resultados permitieron confirmar que la señalización inducida por ET es activada durante la infección por Fol y además necesaria para la expresión de síntomas (Di et al., 2017). Adicionalmente, al realizar la observación de la expresión de los genes PTI4 y ERF4 en las plantas transgénicas NahG (deficientes en acumulación de AS), se encontró que era menor que en las plantas control de tomate susceptibles a Fol, con lo que se demostró que la ruta del AS es necesaria para que se activen los genes PTI4 y ERF4 pertenecientes a la ruta de señalización del ET (Di et al., 2017).

El modelo propuesto por Di et al., (2017), de la red hormonal en la activación de respuestas de defensa en plantas de tomate frente a $\mathrm{Fol}$, se muestra en la figura 5 .

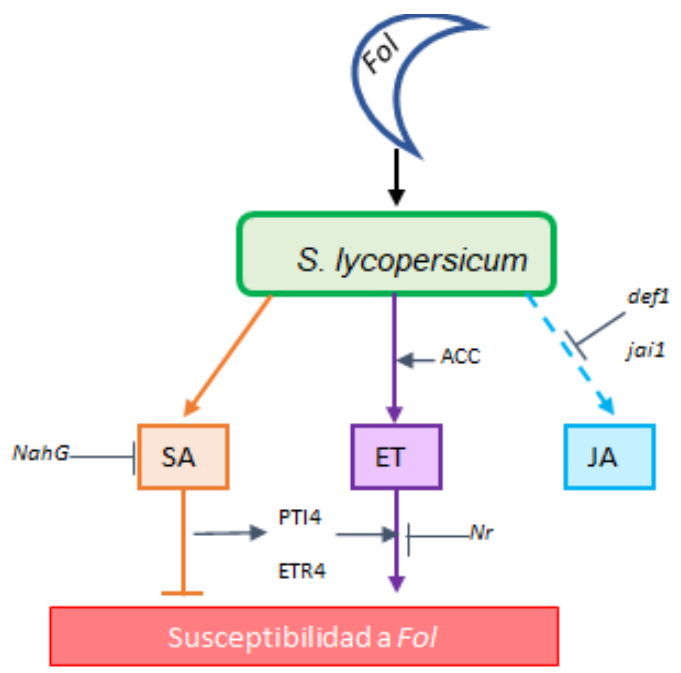

Figura 5. Modelo de la red hormonal en la activación de respuestas de defensa en tomate (Solanum lycopersicum) a Fusarium oxysporum f. sp. lycopersici (Fol). Las barras truncadas representan regulación negativa. Las flechas representan regulación

\section{CONCLUSIONES}

La interacción tomate-Fol y la respuesta en fisiología y mecanismos genéticos de la planta se puede resumir en el modelo descrito en la figura 6. La primera parte del proceso es la invasión por $\mathrm{Fol}$ penetrando la epidermis y luego el córtex radical, hasta llegar al xilema (1). Sus estructuras crecen y se propagan ascendiendo por el xilema donde empieza a liberar micotoxinas como el ácido fusárico. La planta se defiende generando gomas y tilosas, lo cual, junto con las estructuras del hongo, bloquean los haces vasculares y restringen el flujo de agua, disminuyendo el potencial hídrico xilemático (2). Las limitaciones hídricas y la respuesta oxidativa generada por la presencia del patógeno y el ácido fusárico, inducen el cierre estomático, con la consecuente limitación en la toma de $\mathrm{CO}_{2}$; esto disminuye la síntesis de ATP y NADPH, y causa la acumulación de un exceso de energía por falta de aceptores de electrones en el aparato fotosintético. En consecuencia, los centros de reacción se cierran y el exceso de energía es disipada en forma de calor y fluorescencia. El ácido fusárico que puede movilizarse hasta las hojas y los cloroplastos, la acumulación de energía, la producción de ROS por procesos metabólicos y de respuesta de defensa ocasiona cascadas oxidativas que, de no ser reguladas por el sistema antioxidante, generan daño en las membranas y en el aparato fotosintético (3). La modulación hormonal regula la resistencia o la susceptibilidad de la planta. En presencia de $\mathrm{Fol}$, la planta de tomate aumenta su respuesta mediada por AS para inducir resistencia, mientras que el ET aumenta y se relaciona con la susceptibilidad. El rol del AJ no está suficientemente claro, pero es posible que interactúe con AS en parte de la respuesta de defensa. La severidad y extensión de todas las alteraciones mencionadas, puede llevar a muerte celular en los tejidos y la posterior muerte de la planta cuando la interacción tomate - Fol es compatible. 


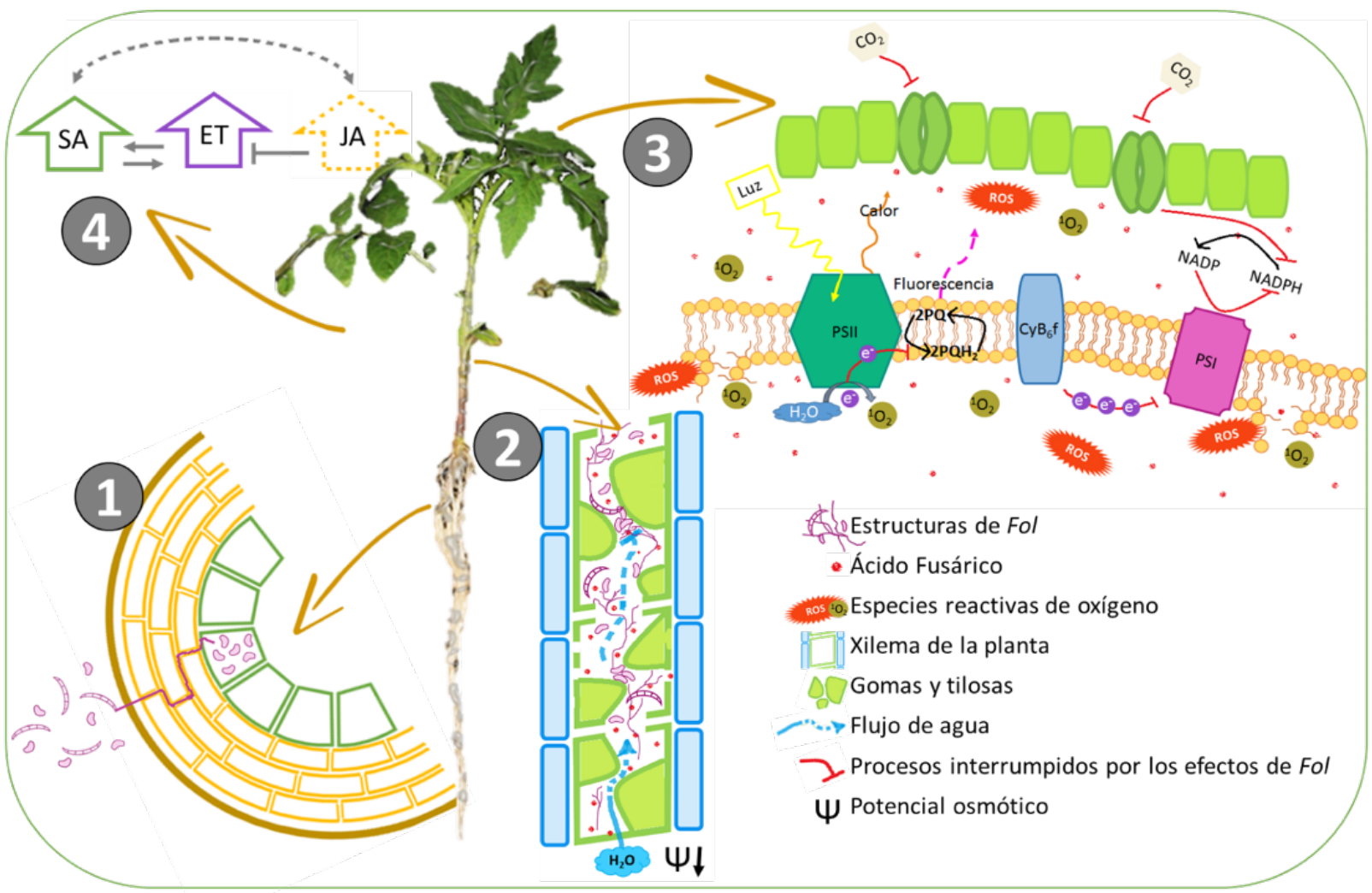

Figura 6. Modelo de las alteraciones fisiológicas en la interacción Tomate- Fol. 1) Invasión de la planta; 2) ascenso por los haces vasculares; 3) alteraciones estomáticas y a nivel de cloroplasto; 4) modulación hormonal. (Fuente propia)

\section{Conflicto de Intereses}

Los autores declaran que es un trabajo original y no existió conflicto de intereses de ningún tipo en la elaboración y publicación del manuscrito.

\section{REFERENCIAS}

Abbashar, A. M. 2003. Investigations On Fusarium oxysporum f. sp. lycopersici The Casual Agent Of Tomato Wilt (Lycopersicon esculentum Mill) (Issue March). University of Khartoum.

Ádám, A., Nagy, Z., Kátay, G., Mergenthaler, E. and Viczián, O. 2018. Signals of Systemic Immunity in Plants: Progress and Open Questions. International Journal of Molecular Sciences, 19(4), 1146. https://doi.org/10.3390/ijms19041146
Agronet. 2020. Base Agrícola EVA 2007-2019 (P)_12_02_2020.

Akhter, A., Hage-Ahmed, K., Soja, G. and Steinkellner, S. 2015. Compost and biochar alter mycorrhization, tomato root exudation, and development of Fusarium oxysporum f. sp. lycopersici. Frontiers in Plant Science, 6, 529.

https://doi.org/10.3389/fpls.2015.00529

Alsamir, M., Mahmood, T., Ahmad, N. and Trethowan, R. 2017. Distribution of organic metabolites after Fusarium wilt incidence in tomato (Solanum esculentum L.). Australian Journal of Crop Science, 11(9): 1123-1129. https://doi.org/10.21475/ajcs.17.11.09. pne536

Andersen, E., Ali, S., Byamukama, E., Yen, Y. and Nepal, M. 2018. Disease Resistance Mechanisms in Plants. Genes, 9(7): 339. https://doi.org/10.3390/genes9070339 
Arbona, V., Argamasilla, R. and Gómezcadenas, A. 2010. Common and divergent physiological, hormonal and metabolic responses of Arabidopsis thaliana and Thellungiella halophila to water and salt stress. Journal of Plant Physiology, 167(16):1342-1350.

https://doi.org/10.1016/j. jplph.2010.05.012

Ashraf, M. and Foolad, M. R. 2007. Roles of glycine betaine and proline in improving plant abiotic stress resistance. Environmental and Experimental Botany, 59(2): 206-216.

https://doi.org/10.1016/j. envexpbot.2005.12.006

Atkinson, N. and Urwin, P. 2012. The interaction of plant biotic and abiotic stresses: from genes to the field. Journal of Experimental Botany, 63(10): 3523-3544.

https://doi.org/10.1093/jxb/err313

Azcón-Bieto, J. and Talón, M. 2008. Fundamentos de fisiología vegetal. In McGrawHill.

https://doi.org/10.1017/ CBO9781107415324.004

Baker, N. R. 2008. Chlorophyll Fluorescence: A Probe of Photosynthesis In Vivo. Annual Review of Plant Biology, 59(1): 89-113.

https://doi.org/10.1146/annurev. arplant.59.032607.092759

Basco, M. J., Bisen, K., Keswani, C. y Singh, H. B. 2017. Biological management of Fusarium wilt of tomato using biofortified vermicompost. Mycosphere, 8(3): 467483.

https://doi.org/10.5943/ $\underline{\text { mycosphere/8/3/8 }}$

Beckers, G. J. and Conrath, U. 2007. Priming for stress resistance: from the lab to the field. Current Opinion in Plant Biology, 10(4): 425-431.

https://doi.org/10.1016//. $\underline{\mathrm{PBI} .2007 .06 .002}$

Ben Rejeb, K., Abdelly, C. and Savouré, A. 2014. How reactive oxygen species and proline face stress together. Plant Physiology and Biochemistry, 80: 278-284.

https://doi.org/10.1016/j. plaphy.2014.04.007
Berger, S., Papadopoulos, M., Schreiber, U., Kaiser, W. and Roitsch, T. 2004. Complex regulation of gene expression, photosynthesis and sugar levels by pathogen infection in tomato. Physiologia Plantarum, 122(4): 419-428.

https://doi.org/10.1111/j.13993054.2004.00433.x

Boix-Ruíz, A., Gálvez-Patón, L., de Cara-García, M., Palmero-Llamas, D., CamachoFerre, F. and Tello-Marquina, J. C. 2015. Comparison of analytical techniques used to identify tomato-pathogenic strains of Fusarium oxysporum. Phytoparasitica, 43(4): 471-483.

https://doi.org/10.1007/s12600-014$\underline{0444-z}$

Boller, T. and Felix, G. 2009. A renaissance of elicitors: perception of microbeassociated molecular patterns and danger signals by pattern-recognition receptors. Annual Review of Plant Biology, 60, 379406.

https://doi.org/10.1146/annurev. arplant.57.032905.105346

Brodersen, C. R. and McElrone, A. J. 2013. Maintenance of xylem Network Transport Capacity: A Review of Embolism Repair in Vascular Plants. Frontiers in Plant Science, 4, 108.

https://doi.org/10.3389/fpls.2013.00108

Carvalhais, L. C., Dennis, P. G., Badri, D. V., Tyson, G. W., Vivanco, J. M. and Śchenk, P. M. 2013. Activation of the Jasmonic Acid Plant Defence Pathway Alters the Composition of Rhizosphere Bacterial Communities. PLoS ONE, 8(2): 1-5. https://doi.org/10.1371/journal. pone.0056457

Catanzariti, A. M., Do, H. T. T., Bru, P., de Sain, M., Thatcher, L. F., Rep, M. and Jones, D. A. 2017. The tomato I gene for Fusarium wilt resistance encodes an atypical leucine-rich repeat receptor-like protein whose function is nevertheless dependent on SOBIR1 and SERK3/BAK1. Plant Journal, 89(6): 1195-1209.

https://doi.org/10.1111/tpj.13458

Chaudhary, R. and Atamian, H. 2017. Resistance-Gene-Mediated Defense Responses against Biotic Stresses in the Crop Model Plant Tomato. Journal of Plant Pathology \& Microbiology, 8(4): $1-11$.

https://doi.org/10.4172/21577471.1000404 
Chaves, M. M., Flexas, J. and Pinheiro, C. 2009. Photosynthesis under drought and salt stress: Regulation mechanisms from whole plant to cell. Annals of Botany, 103(4): 551-560.

https://doi.org/10.1093/aob/mcn125

Chekali, S., Gargouri, S., Paulitz, T., Nicol, J. M., Rezgui, M. and Nasraoui, B. 2011. Effects of Fusarium culmorum and water stress on durum wheat in Tunisia. Crop Protection, 30(6), 718-725.

https://doi.org/10.1016/j. cropro.2011.01.007

Choudhary, D. K. and Varma, A. 2016. Microbial-mediated Induced Systemic Resistance in Plants (D. K. Choudhary \& A. Varma (Eds.); 1st ed.). Springer India.

Clayton, E. E. 1923. The Relation of Temperature to the Fusarium Wilt of the Tomato. American Journal of Botany, 10(2): 71. https://doi.org/10.2307/2435575

Cole, S. J., Yoon, A. J., Faull, K. F. and Diener, A. C. 2014. Host perception of jasmonates promotes infection by Fusarium oxysporum formae speciales that produce isoleucine- and leucine-conjugated jasmonates. Molecular Plant Pathology, 15(6): 589-600.

https://doi.org/10.1111/mpp.12117

Constantin, M. E., de Lamo, F. J., Vlieger, B. V., Rep, M. and Takken, F. L. W. 2019. Endophyte-Mediated Resistance in Tomato to Fusarium oxysporum Is Independent of ET, JA, and SA. Frontiers in Plant Science, 10, 1-14.

https://doi.org/10.3389/fpls.2019.00979

Couto, D. and Zipfel, C. 2016. Regulation of pattern recognition receptor signalling in plants. Nature Reviews Immunology, 16(9): 537-552.

https://doi.org/10.1038/nri.2016.77
Dean, R., Van Kan, J. A. L., Pretorius, Z. A., Hammond-kosack, K. E., Di Pietro, A., Spanu, P. D., Rudd, J. J., Dickman, M., Kahmann, R., Ellis, J. and Foster, G. D. 2012. The Top 10 fungal pathogens in molecular plant pathology. Molecular Plant Pathology, 13(4): 414-430.

https://doi.org/10.1111/j.13643703.2011.00783.x

Dehgahi, R., Subramaniam, S., Zakaria, L., Joniyas, A., Firouzjahi, F. B., Haghnama, K. and Razinataj, M. 2015. Review of Research on Fungal Pathogen Attack and Plant Defense Mechanism against Pathogen. International Journal of Scientific Research in Agricultural Sciences, 2(8): 197-208.

https://doi.org/10.12983/ijsras2015-p0197-0208

Di Pietro, A., Madrid, M. P., Caracuel, Z., Delgado-Jarana, J. and Roncero, $M$. I. G. 2003. Fusarium oxysporum: Exploring the molecular arsenal of a vascular wilt fungus. Molecular Plant Pathology, 4(5): 315-325.

https://doi.org/10.1046/j.13643703.2003.00180.x

Di, X., Gomila, J. O. and Takken, F. L. W. 2017. Involvement of salicylic acid, ethylene and jasmonic acid signalling pathways in the susceptibility of tomato to Fusarium oxysporum. Molecular Plant Pathology, 18(7): 1024-1035.

Dmitriev, a P. 2003. Signal Molecules for Plant Defense Responses to Biotic Stress. Text, 50(3): 417-425.

Doares, S. H., Syrovetst, T., Weilert, E. W. and Ryan, C. A. 1995. Oligogalacturonides and chitosan activate plant defensive genes through the octadecanoid pathway. 92, 4095-4098.

http://www.pnas.org/content/ pnas/92/10/4095.full.pdf

Dong, X., Xiong, Y., Ling, N., Shen, Q. and Guo, S. 2014. Fusaric acid accelerates the senescence of leaf in banana when infected by Fusarium. World Journal of Microbiology and Biotechnology, 30(4): 1399-1408.

https://doi.org/10.1007/s11274-0131564-1 
Duniway, J. 1971. Water relations of Fusarium wilt. Physiology Plant Pathology, 1, 539548.

FAO. 2020. Faostat: Production quantities of Tomatoes by country.

Fraire-Velázquez, S., Rodríguez-Guerra, R. and Sánchez-Calderón, L. 2011. Abiotic and Biotic Stress Response Crosstalk in Plants. In A. Shank (Ed.), Abiotic Stress Response in Plants - Physiological, Biochemical and Genetic Perspectives (InTech Eur, p. 346).

Francia, D. Demaria, D., Calderini, O., Ferraris, L., Valentino, D., Arcioni, S., Tamietti, G. and Cardinale, F. 2007. Wounding induces resistance to pathogens with different lifestyles in tomato: Role of ethylene in cross-protection. Plant, Cell and Environment, 30(11): 1357-1365.

https://doi.org/10.1111/j.1365$\underline{3040.2007 .01709 . x}$

Freitas De Campos, M., Carvalho, K. De, Suano, F., Souza, D. and Jamil, C. 2011. Drought tolerance and antioxidant enzymatic activity in transgenic ' Swingle 'citrumelo plants over-accumulating proline. Environmental and Experimental Botany, 72, 242-250.

https://doi.org/10.1016/j. envexpbot.2011.03.009

García-Enciso, E. L., Benavides-Mendoza, A., Flores-López, M. L., Robledo-Olivo, A., Juárez-Maldonado, $A$. and GonzálezMorales, S. 2018. A Molecular Vision of the Interaction of Tomato Plants and Fusarium oxysporum f. sp. lycopersic. In Fusarium - Plant Diseases, Pathogen Diversity, Genetic Diversity, Resistance and Molecular Markers. InTech.

https://doi.org/10.5772/ intechopen.72127

Goltsev, V. N., Kalaji, H. M., Paunov, M., Bąba, W., Horaczek, T., Mojski, J., Kociel, H. and Allakhverdiev, S. I. 2016. Variable chlorophyll fluorescence and its use for assessing physiological condition of plant photosynthetic apparatus. Russian Journal of Plant Physiology, 63(6), 869-893.

https://doi.org/10.1134/ S1021443716050058
Gonzalez-Cendales, Y., Catanzariti, A.-M., Baker, B., Mcgrath, D. J. and Jones, D. A. 2016. Identification of I-7 expands the repertoire of genes for resistance to Fusarium wilt in tomato to three resistance gene classes. Molecular Plant Pathology, 17(3): 448-463. https://doi.org/10.1111/mpp.12294

Henry, G., Thonart, P. and Ongena, M. 2012. PAMPs, MAMPs, DAMPs and others: an update on the diversity of plant immunity elicitors. Biotechnologie, Agronomie, Société et ..., 16(2), 12.

Houterman, P. M., Cornelissen, B. J. C. and Rep, M. 2008. Suppression of plant resistance gene-based immunity by a fungal effector. PLoS Pathogens, 4(5):1-6. https://doi.org/10.1371/journal. ppat.1000061

Huot, B., Yao, J., Montgomery, B. L. and He, S. Y. 2014. Growth-defense tradeoffs in plants: A balancing act to optimize fitness. Molecular Plant, 7(8): 1267-1287. https://doi.org/10.1093/mp/ssu049

Inami, K., Yoshioka-Akiyama, C., Morita, Y., Yamasaki, M., Teraoka, T. and Arie, T. 2012. A Genetic Mechanism for Emergence of Races in Fusarium oxysporum f. sp. lycopersici: Inactivation of Avirulence Gene AVR1 by Transposon Insertion. PLoS ONE, 7(8), e44101.

https://doi.org/10.1371/journal. pone.0044101

Ito, S. ichi, Ihara, T., Tamura, H., Tanaka, S., Ikeda, T., Kajihara, H., Dissanayake, C., Abdel-Motaal, F. F. and El-Sayed, M. A. 2007. $\alpha$-Tomatine, the major saponin in tomato, induces programmed cell death mediated by reactive oxygen species in the fungal pathogen Fusarium oxysporum. FEBS Letters, 581(17): 3217-3222.

https://doi.org/10.1016/j. febslet.2007.06.010

Jayamohan, N. S., Patil, S. V. and Kumudini, B. S. 2018. Reactive oxygen species (ROS) and antioxidative enzyme status in Solanum lycopersicum on priming with fluorescent Pseudomonas spp. against Fusarium oxysporum. Biologia, 73(11): 1073-1082.

https://doi.org/10.2478/s11756-018$\underline{0125-3}$ 
Jiao, J., Zhou, B., Zhu, X., Gao, Z. and Liang, Y. 2013. Fusaric acid induction of programmed cell death modulated through nitric oxide signalling in tobacco suspension cells. Planta, 238(4): 727737.

https://doi.org/10.1007/s00425-0131928-7

Jogaiah, S., Abdelrahman, M., Tran, L. S. P. and Ito, S. I. 2018. Different mechanisms of Trichoderma virens-mediated resistance in tomato against Fusarium wilt involve the jasmonic and salicylic acid pathways. Molecular Plant Pathology, 19(4): 870882.

https://doi.org/10.1111/mpp.12571

Jones, D. and Takemoto, D. 2004. Plant innate immunity - direct and indirect recognition of general and specific pathogenassociated molecules. Current Opinion in Immunology, 16(1): 48-62.

https://doi.org/10.1016/j. coi.2003.11.016

Jones, J. D. G. and Dangl, J. L. 2006. The plant immune system. Nature Reviews, 444, 323-329.

https://doi.org/10.1038/nature05286

Jones, J. D. G., Vance, R. E. and Dangl, J. L. 2016. Intracellular innate immune surveillance devices in plants and animals. In Science 354 (6316): 1-8. American Association for the Advancement of Science. https://doi.org/10.1126/science.aaf6395

Kavroulakis, N., Doupis, G., Papadakis, I. E., Ehaliotis, C. and Papadopoulou, K. K. 2018. Tolerance of tomato plants to water stress is improved by the root endophyte Fusarium solani FsK. Rhizosphere, 6, 7785.

https://doi.org/10.1016/j. rhisph.2018.04.003

Kavroulakis, N., Ntougias, S., Zervakis, G. I., Ehaliotis, C., Haralampidis, K. and Papadopoulou, K. K. 2007. Role of ethylene in the protection of tomato plants against soil-borne fungal pathogens conferred by an endophytic Fusarium solani strain. Journal of Experimental Botany, 58(14): 3853-3864.

https://doi.org/10.1093/jxb/erm230
Kiirika, L. M., Stahl, F. and Wydra, K. 2013. Phenotypic and molecular characterization of resistance induction by single and combined application of chitosan and silicon in tomato against Ralstonia solanacearum. Physiological and Molecular Plant Pathology, 81, 1-12. https://doi.org/10.1016/j. pmpp.2012.11.002

Król, P., Igielski, R., Pollmann, S. and Kepczyńska, E. 2015. Priming of seeds with methyl jasmonate induced resistance to hemi-biotroph Fusarium oxysporum f.sp. lycopersici in tomato via 12-oxophytodienoic acid, salicylic acid, and flavonol accumulation. Journal of Plant Physiology, 179, 122-132.

https://doi.org/10.1016/j. jplph.2015.01.018

Kumar, A. and Verma, J. P. 2018. Does plant Microbe interaction confer stress tolerance in plants: A review? Microbiological Research, 207, 41-52.

https://doi.org/10.1016/j. micres.2017.11.004

Latowski, D., Surówka, E. and Strzałka, K. 2010. Regulatory Role of Components of Ascorbate Glutathione Pathway in Plant Stress Tolerance. In N. A. Anjum, S. Umar, \& M.-T. Chan (Eds.), AscorbateGlutathione Pathway and Stress Tolerance in Plants. 1-443. Springer Netherlands. https://doi.org/10.1007/978-90-4819404-9

Liu, L., Sonbol, F. M., Huot, B., Gu, Y., Withers, J., Mwimba, M., Yao, J., He, S. Y. and Dong, X. 2016. Salicylic acid receptors activate jasmonic acid signalling through a non-canonical pathway to promote effector-triggered immunity. Nature Communications, 7, 1-10.

https://doi.org/10.1038/ncomms13099

López-Díaz, C., Rahjoo, V., Sulyok, M., Ghionna, V., Martín-Vicente, A., Capilla, J., Di Pietro, A. and López-Berges, M. S. 2017. Fusaric acid contributes to virulence of Fusarium oxysporum on plant and mammalian hosts. Molecular Plant Pathology.

https://doi.org/10.1111/mpp.12536 
Lorenzini, G., Guidi, L., Nali, C., Ciompi, S. and Soldatini, G. F. 1997. Photosynthetic response of tomato plants to vascular wilt diseases. Plant Science, 124(2): 143-152. https://doi.org/10.1016/S01689452(97)04600-1

Lund, S. T., Stall, R. E. and Klee, H. J. 1998. Ethylene regulates the susceptible response to pathogen infection in tomato. Plant Cell, 10(3): 371-382.

https://doi.org/10.1105/tpc.10.3.371

Maina, F. M., Hauschild, R. and Sikora, R. 2008. Protection of tomato plants against fusaric acid by resistance induction. In CJournal of Applied Biosciences.1 (1). www.biosciences.elewa.org

Mandal, S., Mallick, N. and Mitra, A. 2009. Salicylic acid-induced resistance to Fusarium oxysporum f. sp. lycopersici in tomato. Plant Physiology and Biochemistry, 47(7):642-649.

https://doi.org/10.1016/j. plaphy.2009.03.001

Manokaran, R. and Jambhulkar, P. P. 2016. Study of induced systemic resistance in tomato against Fusarium oxysporum f. sp lycopersici causing wilt of tomato Study of induced systemic resistance in tomato against Fusarium oxysporum $f$. sp lycopersici causing wilt of tomato. 69, 539-542.

Maqsood, A., Wu, H., Kamran, M., Altaf, H., Mustafa, A., Ahmar, S., Hong, N. T. T., Tariq, K., He, Q. and Chen, J. T. 2020. Variations in growth, physiology, and antioxidative defense responses of two tomato (Solanum lycopersicum L.) cultivars after co-infection of Fusarium oxysporum and Meloidogyne incognita. Agronomy, 10(2):1-25.

https://doi.org/10.3390/ agronomy 10020159

Marín-Ortiz, J. C., Gutierrez-Toro, N., BoteroFernández, V. and Hoyos-Carvajal, L. M. 2020. Linking physiological parameters with visible/near-infrared leaf reflectance in the incubation period of vascular wilt disease. Saudi Journal of Biological Sciences, 27(1): 88-99.

https://doi.org/10.1016/j. sjbs.2019.05.007
Martínez-Medina, A., Fernández, I., SánchezGuzmán, M. J., Jung, S. C., Pascual, J. A. and Pozo, M. J. 2013. Deciphering the hormonal signalling network behind the systemic resistance induced by Trichoderma harzianum in tomato. Frontiers in Plant Science, 4, 1-12. https://doi.org/10.3389/fpls.2013.00206

Maxwell, K. and Johnson, G. N. 2000. Chlorophyll a fluorescence - a practical guide. Journal of Experimental Botany, 51(345): 659-668.

https://doi.org/10.1093/jxb/51.345.659

McGovern, R. J. 2015. Management of tomato diseases caused by Fusarium oxysporum. Crop Protection, 73, 78-92.

https://doi.org/10.1016/j. cropro.2015.02.021

Melgarejo, L. M., Romero, M., Hernandez, S., Barrera, J., Solarte, E., Pérez, V., Rojas, A., Cruz, M., Moreno, L., Crespo, S. and Pérez, W. 2010. Experimentos en Fisiología Vegetal (U. N. de Colombia (Ed.); First edit). Universidad Nacional de Colombia.

Mes, J. J., Van Doorn, A. A., Wijbrandi, J., Simons, G., Cornelissen, B. J. C. and Haring, M. A. 2000. Expression of the Fusarium resistance gene I-2 colocalizes with the site of fungal containment. Plant Journal, 23(2), 183-193.

https://doi.org/10.1046/j.1365313X.2000.00765.X

Michielse, C. B. and Rep, M. 2009. Pathogen profile update: Fusarium oxysporum. Molecular Plant Pathology, 10(3): 311324.

https://doi.org/10.1111/j.13643703.2009.00538.x

Nair, A., Kolet, S. P., Thulasiram, H. V. and Bhargava, S. 2015. Role of methyl jasmonate in the expression of mycorrhizal induced resistance against Fusarium oxysporum in tomato plants. Physiological and Molecular Plant Pathology, 92, 139-145.

https://doi.org/10.1016/j. pmpp.2015.10.002 
Nankishore, A. and Farrell, A. D. 2016. The response of contrasting tomato genotypes to combined heat and drought stress. Journal of Plant Physiology, 202, 75-82. https://doi.org/10.1016/j. jplph.2016.07.006

Narasimhamurthy, K., Soumya, K., Udayashankar, A. C., Srinivas, C. and Niranjana, S. R. 2019. Elicitation of innate immunity in tomato by salicylic acid and Amomum nilgiricum against Ralstonia solanacearum. Biocatalysis and Agricultural Biotechnology, 22. 1-7

https://doi.org/10.1016/j. bcab.2019.101414

Nobori, T., Mine, A. and Tsuda, K. 2018. Molecular networks in plant-pathogen holobiont. FEBS Letters.

https://doi.org/10.1002/18733468.13071

Nogués, S., Cotxarrera, L., Alegre, L. and Trillas, M. I. 2002. Limitations to photosynthesis in tomato leaves induced by Fusarium wilt. New Phytologist, 154(2): 461-470. https://doi.org/10.1046/j.14698137.2002.00379.x

Periyannan, S., Milne, R. J., Figueroa, M., Lagudah, E. S. and Dodds, P. N. 2017. An overview of genetic rust resistance: From broad to specific mechanisms. In PLoS Pathogens 13(7). Public Library of Science.

https://doi.org/10.1371/journal. ppat.1006380

Pieterse, C. M. J., Leon-Reyes, A., van Der Ent, S. and van Wees, S. C. M. 2009. Networking by small-molecule hormones in plant immunity. Nature Chemical Biology, 5(5): 308-316.

https://doi.org/10.1038/nchembio.164

Pieterse, C. M. J., van der Does, D., Zamioudis, C., Leon-Reyes, A. and Van Wees, S. C. M. 2012. Hormonal Modulation of Plant Immunity. Annual Review of Cell and Developmental Biology, 28(1): 489-521. https://doi.org/10.1146/annurevcellbio-092910-154055
Pinheiro, C. and Chaves, M. M. 2011. Photosynthesis and drought: Can we make metabolic connections from available data? Journal of Experimental Botany, 62(3): 869-882. https://doi.org/10.1093/jxb/erq340

Pitzschke, A., Schikora, A. and Hirt, H. 2009. MAPK cascade signalling networks in plant defence. Current Opinion in Plant Biology, 12(4): 421-426.

https://doi.org/10.1016/j. pbi.2009.06.008

Pshibytko, N. L., Zenevich, L. A. and Kabashnikova, L. F. 2006. Changes in the photosynthetic apparatus during Fusarium wilt of tomato. Russian Journal of Plant Physiology, 53(1): 25-31.

Pusztahelyi, T. 2018. Chitin and chitin-related compounds in plant-fungal interactions. Mycology, 9(3): 189-201. https://doi.org/10.1080/21501203.2018. 1473299

Qi, J., Song, C. P., Wang, B., Zhou, J., Kangasjärvi, J., Zhu, J. K. and Gong, Z. 2018. Reactive oxygen species signaling and stomatal movement in plant responses to drought stress and pathogen attack. Journal of Integrative Plant Biology, 60(9): 805-826. https://doi.org/10.1111/jipb.12654

Ramírez-Gómez, M. and Rodríguez, A. 2012. Mecanismos de defensa y respuestas de las plantas en la interacción micorrícica: una revisión. Revista Colombiana de Biotecnología, 14(1): 271-284.

Rep, M., van Der Does, H. C., Meijer, M., Van Wijk, R., Houterman, P. M., Dekker, $H$. L., De Koster, C. G. and Cornelissen, B. J. C. 2004. A small, cysteine-rich protein secreted by Fusarium oxysporum during colonization of xylem vessels is required for 1-3-mediated resistance in tomato. Molecular Microbiology, 53(5): 13731383.

https://doi.org/10.1111/j.13652958.2004.04177.x 
Saharan, V. and Pal, A. 2016. Chitosan Based Nanomaterials in Plant Growth and Protection. Springer India.

Samadi, L. and Behboodi, B. 2006. Fusaric acid induces apoptosis in saffron root-tip cells: roles of caspase-like activity, cytochrome c, and $\mathrm{H}_{2} \mathrm{O}_{2}$. Planta, 225(1), 223-234. https://doi.org/10.1007/s00425-006$\underline{0345-6}$

Shah, J. 2009. Plants under attack: systemic signals in defence. Current Opinion in Plant Biology, 12(4): 459-464.

https://doi.org/10.1016/j. pbi.2009.05.011

Sharif, R., Mujtaba, M., Rahman, M. U., Shalmani, A., Ahmad, H., Anwar, T., Tianchan, D. and Wang, $X$. 2018. The Multifunctional Role of Chitosan in Horticultural crops: a review. Molecules, 23(872): 1-20.

https://doi.org/10.3390/ molecules23040872

Singh, P., Singh, J., Ray, S., Rajput, R. S., Vaishnav, A., Singh, R. K. and Singh, H. B. 2020. Seed biopriming with antagonistic microbes and ascorbic acid induce resistance in tomato against Fusarium wilt Prachi. Microbiological Research, 237.

https://doi.org/10.1016/j. micres.2020.126482

Singh, V. K., Singh, H. B. and Upadhyay, R. S. 2017. Role of fusaric acid in the development of 'Fusarium wilt' symptoms in tomato: Physiological, biochemical and proteomic perspectives. Plant Physiology and Biochemistry, 118, 320-332.

https://doi.org/10.1016/j. plaphy.2017.06.028

Singh, V. K. and Upadhyay, R. S. 2014. Fusaric acid induced cell death and changes in oxidative metabolism of Solanum lycopersicum L. Botanical Studies, 55(1): 66.

https://doi.org/10.1186/s40529-014$\underline{\text { 0066-2 }}$
Soliman, M. H. and El-Mohamedy, R. S. R. 2017. Induction of defense-related physiological and antioxidant enzyme response against powdery mildew disease in okra (Abelmoschus esculentus L.) plant by using chitosan and potassium salts. Mycobiology.

ht tps://do i.org/10.5941/ MYCO.2017.45.4.409

Srinivas, C., Nirmala Devi, D., Narasimha Murthy, K., Mohan, C. D., Lakshmeesha, T. R., Singh, B. P., Kalagatur, N. K., Niranjana, S. R., Hashem, A., Alqarawi, A. A., Tabassum, B., Abd Allah, E. F. and Chandra Nayaka, S. 2019. Fusarium oxysporum f. sp. lycopersici causal agent of vascular wilt disease of tomato: Biology to diversity A review. Saudi Journal of Biological Sciences, 26(7): 1315-1324.

https://doi.org/10.1016/j. sjbs.2019.06.002

Stahl, E., biology, J. B.-C. opinion in plant, and 2000. Plant pathogen arms races at the molecular level. Plant Bioloy. 3(4):299304.

Doi: 10.1016/s1369-5266(00)00083-2

Takken, F. and Rep, M. 2010. The arms race between tomato and Fusarium oxysporum. In Molecular Plant Pathology 11(2):309-314.

https://doi.org/10.1111/j.13643703.2009.00605.x

Thaler, J. S., Humphrey, P. T. and Whiteman, N. K. 2012. Evolution of jasmonate and salicylate signal crosstalk. Trends in Plant Science, 17(5):260-270.

ht tps://do i.org/10.1016/j. tplants.2012.02.010

Tripathy, B. C. hara. and Oelmüller, R. 2012. Reactive oxygen species generation and signaling in plants. Plant Signaling \& Behavior, 7(12): 1621-1633.

https://doi.org/10.4161/psb.22455

Van der Does, H. C., Constantin, M. ., Houterman, P. M., Takken, F. L. W., Cornelissen, B. J. C., Haring, M. A., van den Burg, H. A. and Rep, M. 2018. Fusarium oxysporum colonizes the stem of resistant tomato plants, the extent varying with the R-gene present. European Journal of Plant Pathology, 154. 55-65. 
Van Loon, L. C., Rep, M. and Pieterse, C. M. J. 2006. Significance of Inducible Defenserelated Proteins in Infected Plants. Annual Review of Phytopathology, 44(1), 135-162.

https://doi.org/10.1146/annurev. phyto.44.070505.143425

Vidhyasekaran, P. 2016. Switching on Plant Innate Immunity Signaling Systems - Bioengineering and Molecular Manipulation of PAMP-PIMP-PRR Signaling Complex (F. Baluška \& J. Vivanco (Eds.)). Springer International Publishing AG Switzerland.

https://doi.org/10.1007/978-3-31926118-8

Villa-Martínez, A., Morales-morales, Hugo Armando., Pérez-Leal, R. y Soto-parra, Juan Manuel., Basurto-Sotelo, M. and E. M.-E. 2015. Situación actual en el control de Fusarium spp . y evaluación de la actividad antifúngica de extractos vegetales. Acta Agronomica, 64(2): 194205.

https://doi.org/http://dx.doi. org/10.15446/acag.v64n2.43358

Villarreal, A. del P. 2013. Evaluación fisiológica de plantas de uchuva (Physalis peruviana L.), en la respuesta al estrés por anegamiento e infección de Fusarium oxysporum. 141.

Wagner, A., Michalek, W. and Jamiolkowska, A. 2006. Chlorophyll fluorescence measurements as indicators of fusariosis severity in tomato plants. Agronomy Research, 4(Speciel Issue), 461-464.

Walters, D. R. 2015. Physiological responses of plants to attack. In Crop \& Soil Systems Research Group (Wiley Blac), 1. 248

Walters, M. 2015. The plant innate immune system. Journal of Endocytobiosis and Cell Research, 26, 8-12.

Wang, F., Wu, N., Zhang, L., Ahammed, G. J., Chen, X., Xiang, X., Zhou, J., Xia, X., Shi, K., Yu, J., Foyer, C. H. and Zhou, Y. 2018. Light Signaling-dependent Regulation of Photoinhibition and Photoprotection in Tomato. Plant Physiology, 176, 13111326.

https://doi.org/10.1104/pp.17.01143
Wiesel, L., Newton, A. C., Elliott, I., Booty, D., Gilroy, E. M., Birch, P. R. J. and Hein, I. 2014. Molecular effects of resistance elicitors from biological origin and their potential for crop protection. Frontiers in Plant Science, 5, 655. https://doi.org/10.3389/fpls.2014.00655

Yadeta, K. A. and J. Thomma, B. P. H. 2013. The xylem as battleground for plant hosts and vascular wilt pathogens. Frontiers in Plant Science, 4, 1-12.

https://doi.org/10.3389/fpls.2013.00097

Yang, F., Wang, Y., Wang, J., Deng, W., Liao, L. and Li, M. 2011. Different ecophysiological responses between male and female Populus deltoides clones to waterlogging stress. Forest Ecology and Management, 262(11): 1963-1971.

https://doi.org/10.1016/j. foreco.2011.08.039

Zaynab, M., Fatima, M., Abbas, S., Sharif, Y., Umair, M., Zafar, M. H. and Bahadar, K. 2018. Role of secondary metabolites in plant defense against pathogens. In Microbial Pathogenesis 124, 198-202. Academic Press.

https://doi.org/10.1016/j. micpath.2018.08.034

Zehra, A., Meena, M., Dubey, M. K., Aamir, M. and Upadhyay, R. S. 2017. Synergistic effects of plant defense elicitors and Trichoderma harzianum on enhanced induction of antioxidant defense system in tomato against Fusarium wilt disease. Botanical Studies, 58(1).

https://doi.org/10.1186/s40529-0170198-2

Zhang, H., Zhang, Q., Zhai, H., Gao, S., Yang, L., Wang, Z., Xu, Y., Huo, J., Ren, Z., Zhao, N., Wang, X., Li, J., Liu, Q. and He, S. 2020. IbBBX24 Promotes the Jasmonic Acid Pathway and Enhances Fusarium Wilt Resistance in Sweet Potato. The Plant Cell, tpc.00641.2019.

https://doi.org/10.1105/tpc.19.00641 